\title{
The role of adipose tissue secretion in the creation and pain level in osteoarthritis
}

\author{
Alireza Askari ${ }^{1}$, Peyman Arasteh ${ }^{2,3}$, Reza Homayounfar ${ }^{3,4}$, Mohamad Mehdi Naghizadeh $^{3}$, \\ Elham Ehrampoush ${ }^{3,4}$, Seyyede Makiye Mousavi ${ }^{5}$, Reza Alipoor ${ }^{6}$
}

${ }^{1}$ Department of Orthopedic surgery, Shiraz University of Medical Sciences, Shiraz, Iran; ${ }^{2}$ Trauma Research Center, Shahid Rajaee Trauma Hospital, Shiraz University of Medical Sciences, Shiraz, Iran; ${ }^{3}$ Noncommunicable Diseases Research Center, Fasa University of Medical Sciences, Fasa, Iran; ${ }^{4}$ Health policy Research Center, Institute of Health, Shiraz University of Medical Sciences, Shiraz, Iran; ${ }^{5}$ Student Research Committee, Fasa University of Medical Sciences, Fasa, Iran; ${ }^{6}$ Student Research Committee, Hormozgan University of Medical Sciences, Bandar Abbas, Iran

E-mail:r_homayounfar@yahoo.com

Objectives. With increasing evidence regarding the metabolic basis of osteoarthritis (OA), we studied the relationship between adipose tissue and OA.

Methods. This study is part of an OA registry in the eastern part of Fars Province, Iran. Overall, 150 patients with OA and 300 sex matched individuals were selected as a control group. They were compared regarding adipokine concentration (leptin, adiponectin, resistin and visfatin), anthropometric indices, the Western Ontario and McMaster universities arthritis index score (WOMAC).

Results. All adipokine levels were higher among OA patients $(p<0.001)$. After adjusting for age, sex, and body mass index (BMI), adipokines showed a significant and positive association with OA (B: 14.12, B: 9.92, B: 24.71 and B: 12.29 for leptin, adiponectin, visfatin, and resistin, respectively; $\mathrm{p}<0.001)$. Except the adiponectin that had a negative relationship with BMI in the OA group $(\mathrm{r}=-0.570, \mathrm{p}<0.001)$, other adipokines had positive relationships with BMI $(\mathrm{r}=0.781$, $\mathrm{p}<0.001 ; \mathrm{r}=0.530, \mathrm{p}<0.001 ; \mathrm{r}=0.549, \mathrm{p}<0.001$ for leptin, visfatin, and resistin, respectively). Only leptin and adiponectin levels were correlated with pain (B: $0.045,-0.079$ and $\mathrm{p}<0.05)$.

Conclusion. The present study shows that aside to the well-known role of mechanical stress in OA pathogenesis (weight load), leptin, adiponectin, visfatin, and resistin, which represent the adipose tissue independent on the weight, may play a chemical role in OA pathogenesis. In addition, leptin and adiponectin may be involved in the pain levels among patients with OA.

Key words: osteoarthritis, adipose tissue, leptin, adiponectin, visfatin, resistin

Osteoarthritis (OA) or degenerative joint disease is the most common joint involving disease, which belongs to the main pain and disability causes in the elderly. The disease is manifested as a pain by decreased range of motion and in more advanced cases by inflammation, joint swelling, total destruction of cartilage, and disability. It has even been associated with diabetes, cardiac events, and death (Hawker et al. 2017).
New findings regarding the pathophysiology of OA have led to the belief that the disease is perhaps associated with age, genetics, trauma, and metabolic diseases (Askari et al. 2017a). It is now known that obesity is associated with increased risk of OA. Data from the National Health and Nutrition Examination Survey I (NHANESI) study (1988) have shown that obese women and men have four- and fivetimes higher risk of developing OA compared to

Corresponding author: Reza Homayounfar, Associate professor, Noncommunicable Diseases Research Center, Fasa University of Medical Sciences, Fasa, Iran; e-mail: r_homayounfar@yahoo.com. 
non-obese women and men, respectively (Anderson and Felson 1988).

Although the exact mechanism, through which OA and obesity are associated, is not completely known, research suggests that mechanical and metabolic factors are involved (Pottie et al. 2006). Regarding the mechanical factors, the joints, especially the cartilage and subchondral bone, are exposed to mechanical pressure (Gabay et al. 2008). Although excess weight can account for the increased risk of $\mathrm{OA}$ in the knee or hip joints, it is very difficult to explain the relationship between the body mass index (BMI) and OA of the hand (Aspden 2010). Furthermore, it has been shown that reduced body fat has greater beneficial effects in the management of patients with knee OA compared to weight reduction (Sowers and Karvonen-Gutierrez 2010).

Metabolic factors including adipokines, blood sugar, hormonal factors, and free radicals, have been shown to play major role in the development and progress of the disease in multiple animal models (Zand et al. 2016). Studies have shown that 59\% of individuals with $\mathrm{OA}$ have metabolic syndrome $(\mathrm{MeS})$, while the prevalence of $\mathrm{MeS}$ in the normal population without OA, is about 23\% (Puenpatom and Victor 2009). Moreover, research has shown that people with MeS usually develop OA at younger ages, exhibit more generalized symptoms, and experience greater pain than those who do not have MeS (Puenpatom and Victor 2009). Dumond et al. (2003) have presented the first evidence regarding the key role of leptin in OA and laid the groundwork for further studies on adipokines as a metabolic link between obesity and OA.

Therefore, it seems that compared to body weight, body adipose tissue has a stronger relationship with the incidence of OA. Accordingly, the present research studied the relationship between hormones secreted by the adipose tissue, which indirectly represent the amount of adipose tissue in the body and provide the adipose tissue with its metabolic features, and OA correlates.

\section{Patients and methods}

Study design. The study protocol was in accordance with the Declaration of Helsinki guidelines and was approved by the Institutional Review Board (IRB) of Fasa University of Medical Sciences (Code: e-9314, 93/12/19). Written consent was obtained from all the participants of the study.

This study is a part of an OA registry in the Eastern part of Fars Province, Iran, termed the Fasa Osteo- arthritis Study (FOAS), which is affiliated to Fasa University of Medical Sciences. One hundred and fifty patients with $\mathrm{OA}$ are currently registered in the program. Registered patients included all individuals who referred to Fasa Hospital since 2013 with a diagnosis of OA. OA was diagnosed based on the having a Kellgren and Lawrence (K\&L) (Schiphof et al. 2008) of more than one within the knee joint. Furthermore, these individuals lacked complaints in other joints.

In the current study, 300 individuals, from those who visited the orthopedic ward of the university infirmary for complications other than joints, were selected as a control group. The inclusion criteria for the control group were the absence of radiographic complications in the knee and hip defined as a Kellgren \& Lawrence score of zero $(\mathrm{K} \& \mathrm{~L}=0)$. Those who took anti-inflammatory, steroidal, or weight-loss medications, had attempted to reduce weight in the past three months or had no complaints in any other joints, were excluded from the study. Members of the control group were matched regarding the gender with the case group.

Measured parameters. After $12 \mathrm{~h}$ participants fasting, the blood samples were taken from all participants at the central laboratory of the University and the sera were extracted immediately. Subjects had light clothing and were bare footed for the related anthropometric measurements. After the subject had a normal expiration, waist circumference (WC) was measured at midpoint of the inferior border to lowest ribs to the anterior superior iliac spine, using an inelastic tape.

Using a stadiometer (Seca 767, Japan), subjects' heights were measured to the nearest $0.1 \mathrm{~cm}$, furthermore using a digital scale (Seca 767, Japan), and subjects' weights were measured to the nearest 0.1 $\mathrm{kg}$. BMI was calculated by dividing weight $(\mathrm{kg})$ by squared height $\left(\mathrm{m}^{2}\right)$.

After participants resting for a minimum of $10 \mathrm{~min}$, using a sphygmomanometer (Erka Perfect Aneroid, Germany), blood pressure (BP) was measured three consecutive times with an interval of $5 \mathrm{~min}$ from the right arm. A mean was calculated from the three measurements and was considered that individuals' final BP. The WC was measured with minimal clothing using the WHO criterion.

The Western Ontario and McMaster universities arthritis index score (WOMAC) was measured and used for evaluating pain within the knee joint among participants (Goggins et al. 2005).

Serum samples were tested for leptin, adiponectin, resistin and visfatin using a commercial ELISA kit (eBioscience, USA) according to the manufacture 
instructions. Minimum hormone concentration at which the ELISA kit was sensitive to detect leptin, adiponectin, resistin and visfatin was $20 \mathrm{pg} / \mathrm{ml}$, $12 \mathrm{pg} / \mathrm{ml}, 3.1 \mathrm{pg} / \mathrm{ml}$ and $12.5 \mathrm{pg} / \mathrm{ml}$, respectively.

Statistical analysis. Data was analyzed using the Statistical Package for Social Sciences software, SPSS for windows, version 22 (SPSS Inc., Chicago, IL, USA). Figures were generated using the R software, version 3.1.2.

Comparison of means of normally distributed quantitative variables between the $\mathrm{OA}$ and control groups was done using the independent $\mathrm{t}$-test. The Chi-square test was used for comparison of qualitative variables.

To evaluate the relationship between adipokine levels and OA status, the linear regression analysis was used, furthermore the regression model was adjusted for age and BMI.

The linear regression analysis was also used to assess the relationship between WOMAC score and OA status and adipokines (leptin, adiponectin, visfatin and resistin). First, each of the adipokines in the regression model was evaluated separately. After considering the strong inter-relationship between adipokines, they were all entered into the regression model simultaneously for estimating the WOMAC score.

All the variables are displayed as means and standard deviations or percentage and frequency, where appropriate. Our statistical inference was based on a $95 \%$ confidence interval (CI) and a p value of $5 \%$.

\section{Results}

Participant characteristics. Table 1 shows demographic characteristics of the 150 patients with OA and 300 participants in the control group. Individuals in the control group were older than those in the OA group $(54.31 \pm 9.1$ vs. $56.48 \pm 9.07$ years old, $\mathrm{p}=0.017)$. Those in the OA group were heavier $(84.60 \pm 10.82 \mathrm{~kg}$ vs. $73.91 \pm 7.30 \mathrm{~kg}, \quad \mathrm{p}<0.001)$ with
Table 1

Baseline characteristics between comparison groups.

\begin{tabular}{|c|c|c|c|}
\hline Variable & $\begin{array}{c}\text { Osteoarthritis } \\
(\mathrm{n}=150)\end{array}$ & $\begin{array}{l}\text { Control } \\
(\mathrm{n}=300)\end{array}$ & p-value \\
\hline Age (years) & $54.31 \pm 9.10$ & $56.48 \pm 9.07$ & 0.017 \\
\hline \multicolumn{4}{|l|}{ Sex } \\
\hline Male & 28 & 55 & \\
\hline Female & 122 & 245 & \\
\hline Weight (kg) & $84.60 \pm 10.82$ & $73.91 \pm 7.30$ & $<0.001$ \\
\hline Waist circumference $(\mathrm{cm})$ & $91.67 \pm 4.87$ & $86.84 \pm 4.48$ & $<0.001$ \\
\hline $\mathrm{K} \& \mathrm{~L}$ & $2.94 \pm 0.48$ & $0 \pm 0$ & $<0.001$ \\
\hline BMI $\left(\mathrm{kg} / \mathrm{m}^{2}\right)$ & $28.78 \pm 2.49$ & $26.54 \pm 2.69$ & $<0.001$ \\
\hline WOMAC & $15.52 \pm 3.23$ & $5.60 \pm 2.63$ & $<0.001$ \\
\hline Leptin (ng/ml) & $51.75 \pm 14.86$ & $32.79 \pm 7.63$ & $<0.001$ \\
\hline Adiponectin $(\mu \mathrm{g} / \mathrm{ml})$ & $20.33 \pm 5.95$ & $10.77 \pm 3.86$ & $<0.001$ \\
\hline Visfatin (ng/ml) & $80.72 \pm 14.60$ & $52.50 \pm 17.41$ & $<0.001$ \\
\hline Resistin (ng/ml) & $21.51 \pm 6.67$ & $7.94 \pm 2.50$ & $<0.001$ \\
\hline
\end{tabular}

Abbreviations: K\&L - Kellgren \& Lawrence; WOMAC -

McMaster universities arthritis index score; BMI - body mass index.

higher WC $(91.67 \pm 4.87 \mathrm{~cm}$ vs. $86.84 \pm 4.48 \mathrm{~cm}$, $\mathrm{p}<0.001)$ and had higher BMI $\left(28.78 \pm 2.49 \mathrm{~kg} / \mathrm{m}^{2}\right.$ vs. $\left.26.54 \pm 2.69 \mathrm{~kg} / \mathrm{m}^{2}, \mathrm{p}<0.001\right)$ than those in the control group. Pain levels (15.52 \pm 3.23 vs. $5.60 \pm 2.63)$, leptin $(51.75 \pm 14.86 \mathrm{ng} / \mathrm{ml}$ vs. $32.79 \pm 7.63 \mathrm{ng} / \mathrm{ml}$ ), adiponectin $(20.33 \pm 5.95 \mu \mathrm{g} / \mathrm{ml}$ vs. $10.77 \pm 3.86 \mu \mathrm{g} / \mathrm{ml})$, visfatin $(80.72 \pm 14.60 \mathrm{ng} / \mathrm{ml}$ vs. $52.50 \pm 17.41 \mathrm{ng} / \mathrm{ml})$ and resisitin levels $(21.51 \pm 6.67 \mathrm{ng} / \mathrm{ml}$ vs. $7.94 \pm 2.50 \mathrm{ng} / \mathrm{ml})$ were all higher in the OA group ( $<0.001$ for all variables) (Table 1).

Adipokine associations. In the linear regression model, after adjusting for age, sex and BMI, all of the hormones had a significant and positive association with OA (B: 14.12, B: 9.92, B: 24.71 and B: 12.29 for leptin, adiponectin, visfatin and resistin, respectively; $\mathrm{p}<0.001)$ (Table 2).

Table 2

Linear regression analysis for adipokine levels based on having osteoarthritis after adjusting for sex, age and BMI.

\begin{tabular}{|c|c|c|c|c|c|c|c|c|}
\hline \multirow[t]{2}{*}{ Variable } & \multicolumn{2}{|c|}{$\begin{array}{c}\text { Leptin } \\
\left.\text { (adj. } \mathrm{R}^{2}=0.726\right)\end{array}$} & \multicolumn{2}{|c|}{$\begin{array}{c}\begin{array}{c}\text { Adiponectin } \\
\left.\text { (adj. } \mathrm{R}^{2}=0.541\right)\end{array}\end{array}$} & \multicolumn{2}{|c|}{$\begin{array}{c}\text { Visfatin } \\
\text { (adj. } \mathrm{R}^{2}=0.495 \text { ) }\end{array}$} & \multicolumn{2}{|c|}{$\begin{array}{c}\text { Resistin } \\
\text { (adj. } \mathrm{R}^{2}=0.782 \text { ) }\end{array}$} \\
\hline & beta & $\mathrm{p}$-value & beta & p-value & beta & $\mathrm{p}$-value & beta & $\mathrm{p}$-value \\
\hline Status (AO) & 14.12 & $<0.001$ & 9.92 & $<0.001$ & 24.71 & $<0.001$ & 12.29 & $<0.001$ \\
\hline Gender (female) & 0.95 & 0.327 & 2.27 & $<0.001$ & 4.14 & 0.040 & 1.17 & 0.016 \\
\hline Age (year) & 0.24 & $<0.001$ & -0.12 & $<0.001$ & 0.27 & 0.006 & 0.01 & $<0.001$ \\
\hline BMI $\left(\mathrm{kg} / \mathrm{m}^{2}\right)$ & 2.40 & $<0.001$ & -0.27 & 0.005 & 1.85 & $<0.001$ & 0.67 & $<0.001$ \\
\hline
\end{tabular}

Abbreviations: AO - osteoarthritis; BMI - body mass index; adj. - adjusted. 
Except of adiponectin that had a negative relationship with BMI in the OA group ( $r=-0.570, p<0.001)$, other adipokines had positive relationships with BMI $(\mathrm{r}=0.781, \mathrm{p}<0.001 ; \mathrm{r}=0.530, \mathrm{p}<0.001 ; \mathrm{r}=0.549, \mathrm{p}<0.001$ for leptin, visfatin, and resistin, respectively).

In the control group, all adipokines, except for adiponectin, had a significant relationship with BMI; however, this relationship was weaker compared to that in the OA group (Figure 1).

Relationship between pain level and adipokines. Initial results suggested that there is a significant relationship between leptin and adiponectin levels with pain in $\mathrm{OA}$ patients. However, considering the strong internal correlation between adipokines, measurements were repeated in the presence of all variables, and results showed that leptin and adiponectin levels were correlated with pain (B: 0.045, $\mathrm{p}=0.014$ and $\mathrm{B}:-0.079, \mathrm{p}=0.006$, respectively). These results when measurements were repeated in the $\mathrm{OA}$ group confirmed only for adiponectin (B: -0.129 and $\mathrm{p}=0.006)$ (Table 3).

\section{Discussion}

In the present study, we studied the relationship between the adipokines and OA and compared findings between individuals with knee joint $\mathrm{OA}$ and a control group. Our results showed that independent from BMI, age, and gender, levels of hormones secreted by the adipose tissue including leptin, adiponectin, visfatin, and resistin were significantly higher among patients compared to the control group. All hormones (except for adiponectin) were positively associated with BMI, which was completely expected as more adipose tissue accumulates in peoples with higher BMI values.
Few studies have evaluated the relationship between the adipose tissue hormones and knee $\mathrm{OA}$ in comparison to control groups. Most studies, in order to reduce the effects of mechanical stress caused by body weight, have either investigated $\mathrm{OA}$ of the hand or have included few factors in their evaluations. However, $\mathrm{OA}$ is the most prevalent in the knee joint compared to other joints. In the Framingham Arthritis Study, 37\% of people over 60 years old had knee arthritis, while about $27 \%$ and $9 \%$ had OA of the hand and the hip joints, respectively (Zhang and Jordan 2010). Therefore, study of the knee joint may hinder more applicable results. Our findings indicate that the relationship between levels of leptin and BMI were much stronger in people with OA compared to the control group, while there was an inverse relationship between adiponectin and BMI in people with OA. The relationships between BMI and resistin and visfatin were also positive, but were not as strong as that between leptin and BMI.

For a long time, OA was considered as an exclusive outcome of excess weight bear on joints. After Puenpatom and Victor (2009) have suggested for the first time that MeS may be associated with OA, multiple studies have documented a relationship between $\mathrm{OA}$ and MeS components (Askari et al. 2016), which have led to the introduction of the term of metabolic OA (Courties et al. 2017). Our findings support the notion that a metabolic factor (or factors), independent from weight, is part of the pathogenesis of OA (Askari et al. 2017b).

In the study of Collins et al. (2015) 32 Sprague Dawley rats have been classified to either receive a high fat and sucrose diet or a low fat diet. They found that the limbs without mechanical injury, in the high fat diet group, had similar damage regarding OA

Table 3

Linear regression analysis for WOMAC score based on different adipokines and in both the case and control groups.

\begin{tabular}{|c|c|c|c|c|c|c|c|c|c|c|c|c|}
\hline \multirow[t]{2}{*}{ Variable } & \multicolumn{2}{|c|}{$\begin{array}{c}\text { Leptin } \\
\left.\text { (adj. } \mathrm{R}^{2}=0.767\right)\end{array}$} & \multicolumn{2}{|c|}{$\begin{array}{c}\text { Adiponectin } \\
\left(\text { adj. } R^{2}=0.767\right)\end{array}$} & \multicolumn{2}{|c|}{$\begin{array}{c}\text { Visfatin } \\
\text { (adj. } \mathrm{R}^{2}=0.761 \text { ) }\end{array}$} & \multicolumn{2}{|c|}{$\begin{array}{c}\text { Resistin } \\
\left.\text { (adj. } \mathrm{R}^{2}=0.764\right)\end{array}$} & \multicolumn{2}{|c|}{$\begin{array}{l}\text { OA and Control } \\
\left(\text { adj. } \mathrm{R}^{2}=0.771\right)\end{array}$} & \multicolumn{2}{|c|}{$\begin{array}{c}\text { OA patients } \\
\left(\text { adj. } R^{2}=0.407\right)\end{array}$} \\
\hline & beta & p-value & beta & p-value & beta & p-value & beta & $\mathrm{p}$-value & beta & p-value & beta & p-value \\
\hline Status (AO) & 8.7 & $<0.001$ & 10.51 & $<0.001$ & 9.61 & $<0.001$ & 8.50 & $<0.001$ & 9.221 & $<0.001$ & - & - \\
\hline Gender (female) & 0.85 & 0.017 & 0.57 & 0.113 & 0.78 & 0.031 & 0.89 & 0.013 & 0.690 & 0.057 & 1.507 & 0.047 \\
\hline Age (year) & 0.05 & 0.009 & 0.05 & 0.063 & 0.06 & 0.001 & 0.05 & 0.003 & 0.039 & 0.036 & 0.066 & 0.087 \\
\hline BMI $\left(\mathrm{kg} / \mathrm{m}^{2}\right)$ & 0.08 & 0.272 & 0.20 & 0.001 & 0.23 & $<0.001$ & 0.16 & 0.008 & 0.071 & 0.326 & 0.388 & 0.088 \\
\hline Leptin (ng/ml) & 0.06 & $<0.001$ & - & - & - & - & - & - & 0.0450 & 0.014 & 0.014 & 0.063 \\
\hline Adiponectin $(\mu \mathrm{g} / \mathrm{ml})$ & - & - & -0.09 & 0.001 & - & - & - & - & 0.079 & 0.006 & 0.129 & 0.006 \\
\hline Visfatin (ng/ml) & - & - & - & - & 0.002 & 0.795 & - & - & 0.006 & 0.503 & 0.003 & 0.888 \\
\hline Resisitin (ng/ml) & - & - & - & - & - & - & 0.08 & 0.014 & 0.050 & 0.165 & 0.033 & 0.450 \\
\hline
\end{tabular}

Abbreviations: WOMAC - McMaster universities arthritis index score; OA - osteoarthritis; BMI - body mass index; adj. - adjusted. 


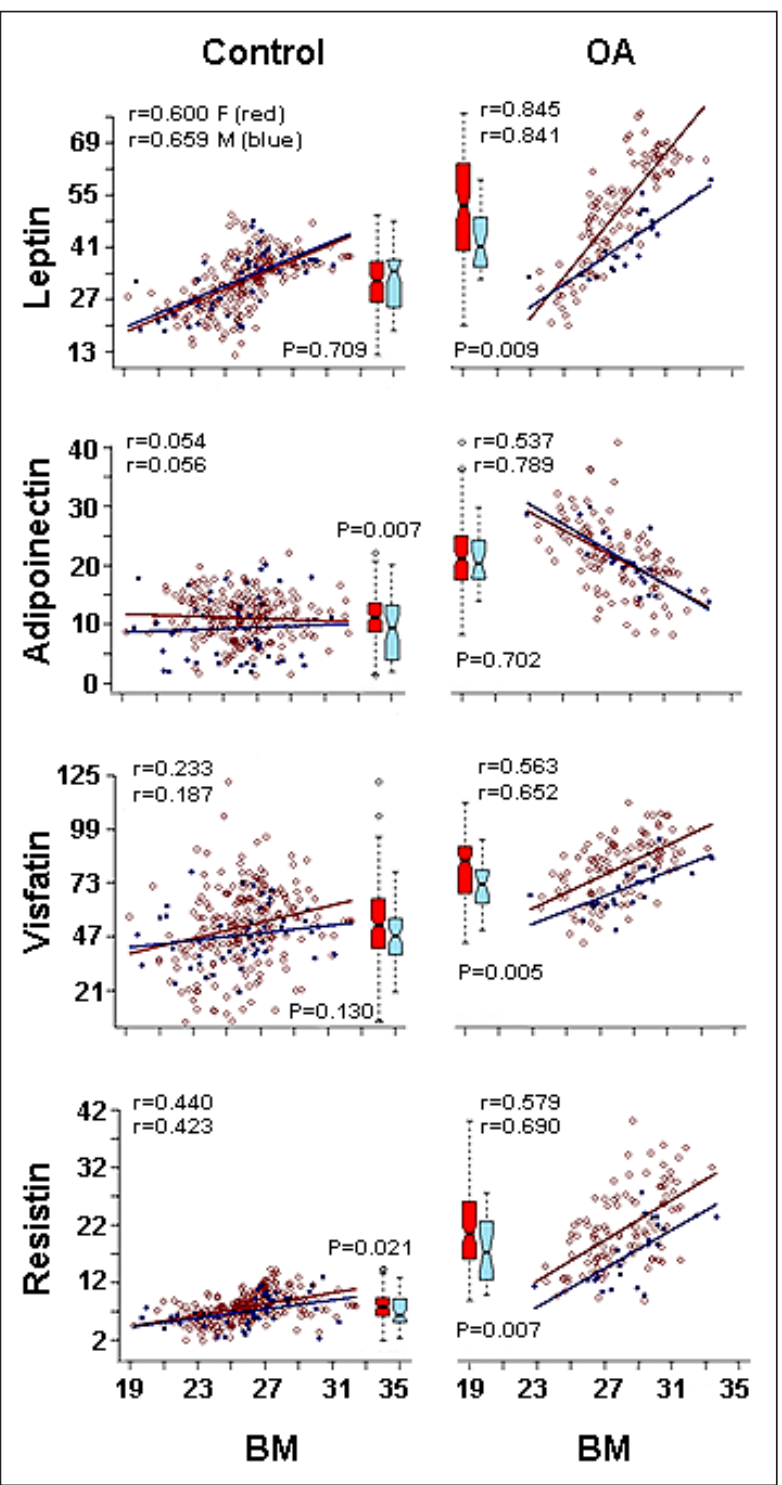

Figure 1. Correlation between body mass index (BMI) and adipokines in both the osteoarthritis (OA) and the control groups.

compared to the limbs with mechanical damage. They attributed this to the synovial fluid leptin levels, total fat percentage, and synovial fluid IP10/CXCL10. Their results are indirectly in support of our findings as we found metabolic mediators of the adipose tissue (adipokines) to be involved in OA.

Griffin et al. (2012) have evaluated a sample of mice with and without high fat diet. They have found that mice who had a very high fat diet had significantly higher leptin levels and higher percentage of adipose tissue, which resulted in higher OA score compared to the control group. They have also found exercise to interrupt pro-inflammatory cytokines indepen- dent from weight or adiposity, in addition exercise improved OA severity in the knee. As some studies in mice have shown that exercise decreases the adipokine expression (Vieira et al. 2009), our findings would indirectly indicate that exercise will improve both OA score and pain among patients with OA through a chemical pathway.

The results of the present study correspond with the data of de Boer et al. (2012). In their study, among 30 patients with end stage knee OA, higher levels of leptin and adiponectin have been observed in the OA group compared to control group (de Boer et al. 2012). Most recent studies support the role of leptin in the homeostasis of joint cartilage and the destruction of joint cartilage involved in OA. In the study of Dumond et al. (2003), it has been shown that leptin was also present in the joint fluid of people with $\mathrm{OA}$ and higher leptin levels were associated with increasing severity of $\mathrm{OA}$ and joint cartilage destruction (Dumond et al. 2003). Studies also suggest that leptin facilitates the production of pre-inflammatory factors and therefore, leptin may be involved in the process of joint inflammation (Bao et al. 2010). In another research $\mathrm{Ku}$ et al. (2009) have found that leptin concentration within the joints was associated with severity of joint diseases in radiographic images. They have suggested that leptin could be used as an effective marker for a quantitative evaluation of $\mathrm{OA}$ (Ku et al 2009). Considering the fact that gene expression related to leptin concentration within the cartilage and leptin levels within the joint fluid are closely associated with BMI, furthermore leptin levels within the joint fluid is higher than leptin serum levels (Presle et al. 2006), which suggests that leptin may be the metabolic link between the obesity and OA.

The role of adiponectin in the pathogenesis of $\mathrm{OA}$ has remained somewhat ambiguous. Adiponectin was once considered as a protective agent, but clinical observations have suggested adiponectin to play a destructive role in the pathogenesis of OA. Plasma adiponectin levels in 35 patients with $\mathrm{OA}$ were considerably higher compared to individuals in a healthy control group (Laurberg et al. 2009). Moreover, in one study (Otero et al. 2006), adiponectin levels were measured in patients with OA and rheumatoid arthritis (RA), they found that leptin levels were higher in RA patients. They have suggested that this increase in adiponectin levels was an attempt to reduce the pre-inflammatory effects caused by leptin (Otero et al. 2006). In addition, adiponectin levels in the synovial fluid in 76 male patients with OA had a direct relationship with disease severity, and adiponectin levels in the joint fluid had a direct relationship 
with aggrecan destruction in 30 female patients with knee OA (Hao et al. 2011). Laboratory studies have further supported the destructive effects of adiponectin in OA through mechanisms similar to that of leptin (Lago et al. 2008). In our study, the overall adiponectin levels in patients with $\mathrm{OA}$ were higher compared to the control group, despite the fact that adiponectin levels decreased with increasing BMI values. Accordingly, we hypothesize that perhaps the adiponectin may be the destructive element that is causing damage within the joints in OA, although adiponectin shows an inverse relation with the severity of osteoarthritis in observational studies, the comparison of its total serum level between the two groups indicates that it is higher in individuals with osteoarthritis (Figure 1). We think that adiponectin may be the key player in the metabolic OA.

We also found that resistin and visfatin levels were significantly higher in OA patients. Although not many studies have evaluated the relationship between resistin and $\mathrm{OA}$, our findings are compatible with them and support the results of the study of de Boer et al. (2012), who have considered resistin aside to leptin and adiponectin. Another study carried out by Choe et al. (2012) have shown that resistin levels in peoples with OA of the hand with radiologic findings, was higher compared to patients with OA of the hand without radiologic findings and compared to a control group. It is believed that resistin is also involved in the pathogenesis of RA. An injection of resistin into the joints of rats causes conditions similar to arthritis. Although in some studies, plasma resistin concentrations in patients with arthritis were similar to that of a healthy control group, other studies have shown that resistin concentrations were higher in the synovial fluid of peoples with arthritis compared to their serum levels, and supported the idea that resistin is involved in the pre-inflammation (Senolt et al. 2007).

Visfatin has been shown to induce chemotaxis and production of IL-1 $\beta$, TNF- $\alpha$, IL- 6 , co-stimulatory molecules by CD14+ monocytes, and increase the ability for alloproliferative response in lymphocytes (Askari et al. 2016). It seems that serum levels of visfatin and its concentration in the synovial fluid are related to the amount of inflammation and severity of disease. After documenting an increase in the circulatory levels of visfatin in patients with RA (Otero et al. 2006), other evidence has suggested that visfatin has a pre-inflammatory role in the chondrocytes and synovial fibroblasts (Gosset et al. 2008), which indicates that visfatin had a role in the joint destruction.
There are few studies concerning the relationship between adipokines and pain levels in patients with OA. Lubbeke et al. (2013) have conducted a crosssectional study, in which 219 patients with OA were included. They have reported a weak correlation between leptin levels of synovial fluid and pain in the joints $(\mathrm{r}=-0.182)$. Massengale et al. (2012) have also reported that leptin and BMI were the only factors associated with pain in patients with OA of the hand, and resistin, and adiponectin did not exhibit any relationship with pain levels. However, we found that after adjusting for age, gender, and BMI, leptin and adiponectin had a significant association with the pain levels, but in OA group, only adiponectin had a significant relation to pain (Table 3 ).

This study was not without limitation. Although the study is a part of an ongoing population-based registry, the cross-sectional nature of the present study did not allow a complete evaluation of factors, which may have affected adipose tissue hormone levels among the study population. Another issue relates to the definition of the control group. Referring to the clinic data, individuals with no OA complications were included into this group. These participants cannot be considered to be "healthy individuals". However, we did adjust for BMI, age, and sex in our analysis to minimize these effects. In the present study, we only considered the role of adipokines and not the adipose tissue percentage itself. However, future studied would benefit from including both adiposity and adipokines in their assessments.

As part of the registry, our study included participants from different ethnic groups and although we did not include these ethnic groups in our analysis, this provided good heterogeneity for our study. In addition, our findings provide strong support for the role of adipokines in OA pathogenesis and pain levels among these patients and this is especially important in populations that have high metabolic disease rates like our study population (Babai et al. 2016).

The results of the present study showed that hormones secreted by the adipose tissue in peoples with knee OA were higher compared to a control group, which indicates that these hormones probably play a role in OA pathogenesis. As for the pain levels, only adiponectin levels had a significant relationship with the pain levels after adjusting for age, gender, and BMI. This suggests that pain levels in patients with OA may be connected to adiponectin levels. In conclusion, the role of the adipose tissue should be regarded in the development of OA and/or pain associated with $\mathrm{OA}$ alongside mechanical stress resulting from excess weight. 


\section{Acknowledgements}

This work is part of a large registry of osteoarthritis patients in the south east of Fars province, Iran, which is funded by Fasa University of Medical Sciences. Clinical research development unit supports the project by the grant number 93128 and it was approved by the Fasa University of Medical Sciences Ethics Committee (Ethical approval code: e-9314). There is no independent financial support for the current work. Other study results of the registry are in press.

\section{References}

Anderson JJ, Felson DT. Factors associated with osteoarthritis of the knee in the first national Health and Nutrition Examination Survey (HANES I) evidence for an association with overweight, race, and physical demands of work. Am J Epidemiol 128, 179-189, 1988.

Askari A, Naghizadeh MM, Homayounfar R, Shahi A, Afsarian MH, Paknahad A, Kennedy D, Ataollahi MR. Increased serum levels of IL-17A and IL-23 are associated with decreased vitamin D3 and increased pain in osteoarthritis. PLoS One 11, e0164757, 2016.

Askari A, Ehrampoush E, Homayounfar R, Bahramali E, Farjam M. Serum insulin in pathogenesis and treatment of osteoarthritis. Med Hypotheses 99, 45-46, 2017a.

Askari A, Ehrampoush E, Homayounfar R, Arasteh P, Naghizadeh MM, Yarahmadi M, Tarbiat N, Eghbali SS. Relationship between metabolic syndrome and osteoarthritis: The Fasa Osteoarthritis Study. Diabetes Metab Syndr 11 Suppl 2, S827-S832, 2017b.

Aspden RM. Obesity punches above its weight in osteoarthritis. Nat Rev Rheumatol 7, 65-68, 2010.

Babai MA, Arasteh P, Hadibarhaghtalab M, Naghizadeh MM, Salehi A, Askari A, Homayounfar R. Defining a BMI cut-off point for the Iranian population: the Shiraz Heart Study. PloS One 11, e0160639, 2016.

Bao JP, Chen WP, Feng J, Hu PF, Shi ZL, Wu LD. Leptin plays a catabolic role on articular cartilage. Mol Biol Rep 37, $3265-3272,2010$

Choe JY, Bae J, Jung HY, Park SH, Lee HJ, Kim SK. Serum resistin level is associated with radiographic changes in hand osteoarthritis: cross-sectional study. Joint Bone Spine 79, 160-165, 2012.

Collins KH, Reimer RA, Seerattan RA, Leonard TR, Herzog W. Using diet-induced obesity to understand a metabolic subtype of osteoarthritis in rats. Osteoarthritis Cartilage 23, 957-965, 2015.

Courties A, Sellam J, Berenbaum F. Metabolic syndrome-associated osteoarthritis. Curr Opin Rheumatol 29, 214222, 2017.

de Boer TN, van Spil WE, Huisman AM, Polak AA, Bijlsma JW, Lafeber FP, Mastbergen SC. Serum adipokines in osteoarthritis; comparison with controls and relationship with local parameters of synovial inflammation and cartilage damage. Osteoarthritis Cartilage 20, 846-853, 2012.

Dumond H, Presle N, Terlain B, Mainard D, Loeuille D, Netter P, Pottie P. Evidence for a key role of leptin in osteoarthritis. Arthritis Rheum 48, 3118-3129, 2003.

Gabay O, Hall DJ, Berenbaum F, Henrotin Y, Sanchez C. Osteoarthritis and obesity: experimental models. Joint Bone Spine 75, 675-679, 2008.

Goggins J, Baker K, Felson D. What WOMAC pain score should make a patient eligible for a trial in knee osteoarthritis? J Rheumatol 32, 540-542, 2005.

Gosset M, Berenbaum F, Salvat C, Sautet A, Pigenet A, Tahiri K, Jacques C. Crucial role of visfatin/pre-B cell colonyenhancing factor in matrix degradation and prostaglandin E2 synthesis in chondrocytes: Possible influence on osteoarthritis. Arthritis Rheum 58, 1399-1409, 2008.

Griffin TM, Huebner JL, Kraus VB, Yan Z, Guilak F. Induction of osteoarthritis and metabolic inflammation by a very high-fat diet in mice: effects of short-term exercise. Arthritis Rheum 64, 443-453, 2012.

Hao D, Li M, Wu Z, Duan Y, Li D, Qiu G. Synovial fluid level of adiponectin correlated with levels of aggrecan degradation markers in osteoarthritis. Rheumatol Int 31, 1433-1437, 2011.

Hawker GA, Croxford R, Bierman AS, Harvey P, Ravi B, Kendzerska T, Stanaitis I, King LK, Lipscombe L. Osteoarthritis-related difficulty walking and risk for diabetes complications. Osteoarthritis Cartilage 25, 67-75, 2017.

$\mathrm{Ku}$ JH, Lee CK, Joo BS, An BM, Choi SH, Wang TH, Cho HL. Correlation of synovial fluid leptin concentrations with the severity of osteoarthritis. Clin Rheumatol 28, 1431-1435, 2009.

Lago R, Gomez R, Otero M, Lago F, Gallego R, Dieguez C, Gomez-Reino JJ, Gualillo O. A new player in cartilage homeostasis: adiponectin induces nitric oxide synthase type II and pro-inflammatory cytokines in chondrocytes. Osteoarthritis Cartilage 16, 1101-1109, 2008. 
Laurberg TB, Frystyk J, Ellingsen T, Hansen IT, Jorgensen A, Tarp U, Hetland ML, Horslev-Petersen K, Hornung N, Poulsen JH, Flyvbjerg A, Stengaard-Pedersen K. Plasma adiponectin in patients with active, early, and chronic rheumatoid arthritis who are steroid-and disease-modifying antirheumatic drug-naive compared with patients with osteoarthritis and controls. J Rheumatol 36, 1885-1891, 2009.

Lubbeke A, Finckh A, Puskas GJ, Suva D, Ladermann A, Bas S, Fritschy D, Gabay C, Hoffmeyer P. Do synovial leptin levels correlate with pain in end stage arthritis? Int Orthop 37, 2071-2079, 2013.

Massengale M, Lu B, Pan JJ, Katz JN, Solomon DH. Adipokine hormones and hand osteoarthritis: radiographic severity and pain. PLoS One 7, e47860, 2012.

Otero M, Lago R, Gomez R, Lago F, Dieguez C, Gomez-Reino JJ, Gualillo O. Changes in plasma levels of fat-derived hormones adiponectin, leptin, resistin and visfatin in patients with rheumatoid arthritis. Ann Rheum Dis 65, 1198-1201, 2006

Pottie P, Presle N, Terlain B, Netter P, Mainard D, Berenbaum F. Obesity and osteoarthritis: more complex than predicted! Ann Rheum Dis 65, 1403-1405, 2006.

Presle N, Pottie P, Dumond H, Guillaume C, Lapicque F, Pallu S, Mainard D, Netter P, Terlain B. Differential distribution of adipokines between serum and synovial fluid in patients with osteoarthritis. Contribution of joint tissues to their articular production. Osteoarthritis Cartilage 14, 690-695, 2006.

Puenpatom RA, Victor TW. Increased prevalence of metabolic syndrome in individuals with osteoarthritis: an analysis of NHANES III data. Postgrad Med 121, 9-20, 2009.

Schiphof D, Boers M, Bierma-Zeinstra SM. Differences in descriptions of Kellgren and Lawrence grades of knee osteoarthritis. Ann Rheum Dis 67, 1034-1036, 2008.

Senolt L, Housa D, Vernerova Z, Jirasek T, Svobodova R, Veigl D, Anderlova K, Muller-Ladner U, Pavelka K, Haluzik M. Resistin in rheumatoid arthritis synovial tissue, synovial fluid and serum. Ann Rheum Dis 66, 458-463, 2007.

Sowers MR, Karvonen-Gutierrez CA. The evolving role of obesity in knee osteoarthritis. Curr Opin Rheumatol 22, 533-537, 2010.

Vieira VJ, Valentine RJ, Wilund KR, Antao N, Baynard T, Woods JA. Effects of exercise and low-fat diet on adipose tissue inflammation and metabolic complications in obese mice. Am J Physiol Endocrinol Metab 296, E1164-E1171, 2009.

Zand H, Homayounfar R, Cheraghpour M, Jeddi-Tehrani M, Ghorbani A, Pourvali K, Soltani SR. Obesity-induced p53 activation in insulin-dependent and independent tissues is inhibited by beta-adrenergic agonist in dietinduced obese rats. Life Sci 147, 103-109, 2016.

Zhang Y, Jordan JM. Epidemiology of osteoarthritis. Clin Geriatr Med 26, 355-369, 2010. 